This is the final peer-reviewed accepted manuscript of:

Valentina Orlandini, Leonardo Pierobon, Signe Schløer, Andrea De Pascale, Fredrik Haglind,

Dynamic performances of a novel offshore power system integrated with a wind farm,

Energy, Volume 109, 2016, p. 236-247

The final published version is available online at:

http://dx.doi.org/10.1016/j.energy.2016.04.073

(C2016. This manuscript version is made available under the Creative Commons AttributionNonCommercial-NoDerivs (CC BY-NC-ND) 4.0 International License

(http://creativecommons.org/licenses/by-nc-nd/4.0/) 


\title{
Dynamic performances of a novel offshore power system integrated with a wind farm
}

\author{
Valentina Orlandini ${ }^{\mathrm{a}, *}$, Leonardo Pierobon ${ }^{\mathrm{b}}$, Signe Schløer ${ }^{\mathrm{b}}$, Andrea De Pascale ${ }^{\mathrm{a}}$, Fredrik \\ Haglind $^{\mathrm{b}}$ \\ ${ }^{a}$ Department of Industrial Engineering, University of Bologna \\ Viale del Risorgimento 2, 40136 Bologna, Italy \\ ${ }^{b}$ Department of Mechanical Engineering, Technical University of Denmark \\ Building 403, 2800 Kongens Lyngby, Denmark
}

\section{Abstract}

Offshore wind technology is rapidly developing and a wind farm can be integrated with offshore power stations. This paper provides a case study concerning a futuristic platform powered by a wind farm and three combined cycle units consisting of a gas turbine and an organic Rankine cycle (ORC) module. The first aim of this paper is to identify the maximum amount of wind power that can be integrated into the system, without compromising the electric grid balance. The stability of the electric grid is tested using a dynamic model of the power system based on first principles. Additionally, the system has been compared with a simplified plant consisting of three gas turbines and a wind farm, in order to identify benefits of the installation of the ORC system. $10 \mathrm{MW}$ is the maximum wind power allowed for a nominal platform load of $30 \mathrm{MW}$. The results suggest that the presence of the ORC system permits to decrease frequency oscillations and fuel consumptions of the platform, with respect to the simplified configuration. On the other hand, the dynamic response of the combined cycles power plant is slower due to the thermal inertia of the heat transfer equipment.

Keywords: Oil and gas, Organic Rankine cycle, Gas turbine, Offshore wind, Integrated system

\section{Introduction}

Offshore oil and gas facilities use inefficient power systems to supply the energy demand on board. The primary objective of platform operators is to ensure a continuous fuel production with minimum risk of failure for the plant. Gas turbines (GTs) are the leading technology

\footnotetext{
${ }^{*}$ Corresponding author

Email address: valentina orlandini2@unibo.it (Valentina Orlandini)
} 
on-board offshore platforms since they offer high reliability, compactness and dynamic flexibility. On the other hand, the large ratios of the work-to-heat demand impede to adequately use the exhaust energy for heating purposes. Moreover, conservative operational strategies further deteriorate the energy conversion efficiency during part-load activities.

Pollutant reduction and sustainable production are slowly arising as important concerns in the oil and gas sector [1]. Carbon tax on combustibles has constituted the primary resource for governments to explore the vast potentials in fuel saving and efficiency increase. For instance, Norway levies carbon tax on hydrocarbon fuels since 1991. In 2013, the Norwegian parliament adopted a forceful measure to alleviate the environmental footprint in the oil and gas industry by doubling the taxation to $55 \$$ per ton of carbon dioxide $\left(\mathrm{CO}_{2}\right)$ [2]. A direct remedy is the removal of on-board power generators by relaying on conveyance of electricity from onshore. Recent surveys [3, 4] and operational experience on actual facilities (e.g. the Troll A platform in the North Sea [5]) have proved the economic feasibility of high-voltage direct current systems for low transportation ranges $(\approx 300 \mathrm{~km})$. Capturing and storing the $\mathrm{CO}_{2}$ is also a solution to reduce emissions offshore. Floating plants with large power outputs (up to $450 \mathrm{MW}$ ) for offshore electrification integrating compression, pre-conditioning and $\mathrm{CO}_{2}$ capture are under investigation $[6,7]$. A drawback is that the sequestration process penalizes the energy conversion efficiency (up to $9 \%$-points [6]). Furthermore, this process does not cope with the removal of other pollutants such as sulfur and nitrogen oxide.

A solution to enhance the system performance is the implementation of a waste heat recovery unit at the bottom of the gas turbines. A mature technology is the steam Rankine cycle (SRC). Kloster [8] described the existing SRC units in the Oseberg, Eldfisk and Snorre B offshore installations. Air bottoming cycles (ABCs) are an alternative to SRC units as they employ a non-toxic and inflammable working fluid. Moreover, $\mathrm{ABC}$ power modules do not require a condenser as they operate as open-cycles. This feature leads to high compactness and low weight. Various studies carried out a feasibility study on the implementation of $\mathrm{ABC}$ units offshore. The results proved a low gain in performance despite the low weight and short payback time $[9,10,11]$. Organic Rankine cycle power systems have recently emerged as suitable technologies $[12,13]$. Favorable design features are their high modularity, compactness and low weight. With ORCs, improvements of the energy conversion efficiency range from $10 \%$ to $20 \%$, with an additional specific weight of $15-20 \mathrm{t} \cdot \mathrm{MW}^{-1}[14]$. 
Research efforts have focused on integrating wind power in oil and gas facilities. The rapid development of offshore wind power technologies enables to design floating turbines for water depths up to $700 \mathrm{~m}$ [15] and distances from the coast of around $100 \mathrm{~km}$ (case of BARD Offshore $1[16])$. The solution is attractive due to the uniform distribution of wind speed and space availability. The integration does not require additional weight and space compared to the implementation of waste heat recovery units or carbon capture technologies. On the other hand, additional challenges related to the stability of the electric network arise, due to the variability of this renewable source. As an example, Årdal et al. [17] and Marvik et al. [18] studied how the presence of wind turbines could improve the stability of an offshore oil and gas platform using voltage controllers. Similarly, He et al. [19] investigated the integration between an offshore oil and gas platform and an offshore wind farm. To the authors' best knowledge, in all previous studies addressing the integration of wind farms on offshore platforms, the platform power plants consist of gas turbines only.

The objective of this paper is to study the dynamic performances of a pioneering oil and gas platform. The stand alone power station comprises an offshore wind farm and three gas turbines, each one coupled with an ORC module. In particular, we aim at answering two research questions: i) what is the maximum number of wind turbines for which the stability of the platform electric grid is not compromised?, and ii) is the implementation of the ORC units beneficial for the plant flexibility? A dynamic model of the power system based on first principles is developed using the Modelica language. The model is integrated with a time series-based model of offshore wind mills. Dynamic tests, e.g., the loss of wind power, are performed to determine the maximum frequency excursions and the variations of control and process variables. The simulations can identify a reasonable size of the wind farm. Additional tests are performed using only the gas turbines to evaluate the effect of the ORC units on the system dynamics.

This paper is structured as follows: Section 2 deals with the description of case study, while the adopted models of the main components of the system are presented in Section 3. Section 4 reports the results and discussions. Conclusive remarks are given in Section 5.

\section{Case study}

This paper considers a generic offshore oil and gas platform located in the North Sea. The floating wind turbines are connected to the stand alone electric grid, see Figure 1(a). The 
wind turbine considered in this work is a reference generator developed at the National Renewable Energy Laboratory (NREL) [20] in USA. The wind turbine is a three-blade upwind variable-speed and variable blade-pitch-to-feather-controlled turbine. The NREL together with the Massachusetts Institute of Technology (USA) is studying a tension leg platform for a floating wind turbine. Pretensioned mooring lines anchored to the seabed by suction piles [21] will connect the corners of the platform, designed for water depths from $60 \mathrm{~m}$ to $200 \mathrm{~m}$ and for a $5 \mathrm{MW}$ turbine. The on board power plant consists of three combined cycle systems, as shown in Figure 1(a). Each one comprises a GT topping module and an ORC bottoming cycle unit. Figure 1(b) shows the layout of the combined cycle unit. The ORC turbogenerator recovers the heat in the exhaust gases of a gas turbine. The SGT-500 gas turbine is considered as topping unit. This engine has been widely adopted on offshore platforms requiring high fuel flexibility and reliability. The twin-spool gas turbine is not cooled and it employs two coaxial shafts coupling the low pressure compressor (LPC) with the low pressure turbine (LPT) and the high pressure compressor (HPC) with the high pressure turbine (HPT). The power turbine (PT) transfers mechanical power through a dedicated shaft to the electric generator (G1). Natural gas is the fuel used in the combustion chamber (CC). Table 1 reports the design-point specifications of the gas turbines as provided by the manufacturer.

The ORC unit comprehends the single-pressure non-reheat once-through boiler (OTB), the turbine (T), the sea-water cooled shell-and-tube condenser (COND) and the feed-water pump (P). The working fluid is benzene (molecular weight $78.11 \mathrm{~kg} / \mathrm{kmol}$, critical temperature and pressure $288.9^{\circ} \mathrm{C}$ and 49.9 bar). This compound is widely adopted for operating ORC systems in this range of temperature, see, e.g., Colonna et al. [22]. The high resonance stabilization energy of the aromatic structure ensures its chemical stability up to $315^{\circ} \mathrm{C}$ [23]. The saturation curve of benzene is positive (dry fluid). A shell-and-tube recuperator is added to decrease the energy contained in the superheated vapor exiting the ORC expander. The in-house simulation tool developed by Pierobon et al [12] is used to design the ORC unit. The software allows to identify the thermodynamic states at the inlet and outlet of each component applying basic energy and mass balances, once defined the boundary conditions. Subsequently, the design of the plant equipment is carried out automatically, ultimately leading to the evaluation of the chosen performance metrics. An iterative procedure, based on the genetic algorithm method explores the design space, looking for optimal design configurations. Table 2 reports the main 
parameters assumed for the considered ORC system, according to the described methodology.

\section{Methods} 6 floating turbines.

\section{3.1. The modeling language}

8

\subsection{The gas turbine}

This part of the paper gives an overview of the adopted modeling language, see Section 3.1. Sections 3.2 and 3.3 present the models of the gas turbine and organic Rankine cycle unit. Section 3.4 describes the model of the wind farm used to calculate the power provided by the

The dynamic model of the power system is developed using components from existing Modelica packages [24]. Modelica is an object-oriented modeling language that allows to build dynamic models using an equation-based modular approach.

The gas turbine sub-system model is built by exploiting basic components included in the ThermoPower library [24]. The model of the ORC system adopts software objects from the Modelica ORC package [25], with suitable adaptations regarding the heat transfer coefficients and flow configuration in the once-through boiler.

Figure 2 shows the Modelica object diagram of the gas turbine. Compressors and turbines are multi-stage machines modeled as zero-dimensional components using steady-state off-design characteristics. The low and high pressure compressors are modeled based on maps of axial compressors provided by Kurzke [26]. These maps, originally from Carchedi and Wood [27], use tables that state values for flow coefficient, pressure ratio, isentropic efficiency and speed of revolution for the complete operating range. The maps are scaled following the methodology proposed by Kurzke [28]. The equation proposed by Stodola [29] is employed for modeling the low pressure, high pressure and power turbines. This equation expresses the relation between the inlet and outlet pressure of the expander with the mass flow rate and the turbine inlet temperature in off-design conditions. The turbine off-design efficiency is predicted with the correlation proposed by Schobeiri [30].

The combustion chamber (CC) unit is built assuming complete and adiabatic combustion process. In the component, mass and energy conservation are expressed including the dynamic 


\subsection{The organic Rankine cycle system}

The once-through boiler, shown in the object diagram of Figure 3, is implemented by combining basic ThermoPower modules. Figure 4 shows the 1D flow models for the gas side (top) and fluid side (bottom of the figure), and the 1D thermal model for the tube bundle (middle). The exchange of thermal power is modeled with so-called 1D thermal ports (in orange in the figure). The counter-current model establishes the topological correspondence between the control volumes on the tube walls, and the control volumes on the gas flow model. The tube 
metal wall of the boiler is modeled by a 1D dynamic heat balance equation, discretized by finite volumes. The flow models contain one-dimensional dynamic mass and energy balance equations, discretized by the finite volume method, assuming a uniform pressure distribution. The relatively small friction losses are lumped in an external component. The pressure drops in off-design conditions are estimated assuming a quadratic dependency with the volumetric flow rate. The thermal resistance in the radial direction and thermal diffusion in the axial direction are neglected due to their relatively small contribution as described by Casella et al. [34]. The heat transfer coefficient between the gas and the outer pipe surface is much lower than the one between the inner pipe surface and the ORC working fluid. Therefore, the overall heat transfer is essentially dependent on the flue gas side only.

The heat transfer coefficient at the interface between the flue gas and the metal wall, in offdesign conditions, is evaluated with the relation proposed by Incropera et al. [35]

$$
h=h_{\mathrm{des}}\left(\frac{\dot{m}}{\dot{m}_{\mathrm{des}}}\right)^{n},
$$

where $h$ is the heat transfer coefficient, $\dot{m}$ the mass flow rate, and the subscript "des" refers to the value at nominal operating conditions. The variable $n$, taken equal to 0.6 , is the exponent of the Reynolds number in the heat transfer correlation. The thermal interaction between the wall and the working fluid is described by specifying a sufficiently high constant heat transfer coefficient.

The turbine is modeled as an equivalent chocked de Laval nozzle. The throat flow passage area is the sum of the throat areas of the nozzles that constitute the first stator row. An isentropic expansion is assumed from the inlet section to the throat, where sonic conditions are attained. The corresponding system of equations is listed below.

$$
\left\{\begin{array}{l}
s_{\mathrm{in}}=s\left(p_{\mathrm{T}, \mathrm{in}}, T_{\mathrm{T}, \mathrm{in}}\right) \\
h_{\mathrm{S}, \mathrm{th}}=h_{\mathrm{T}, \mathrm{in}}\left(p_{\mathrm{T}, \mathrm{in}}, T_{\mathrm{T}, \mathrm{in}}\right)-\frac{1}{2} \cdot c\left(h_{\mathrm{S}, \mathrm{th}}, s_{\mathrm{in}}\right)^{2} \\
\dot{m}=\rho_{\mathrm{S}, \mathrm{th}}\left(h_{\mathrm{S}, \mathrm{th}}, s_{\mathrm{in}}\right) \cdot c\left(h_{\mathrm{S}, \mathrm{th}}, s_{\mathrm{in}}\right) \cdot A_{\mathrm{th}},
\end{array}\right.
$$

where $s_{\text {in }}$ is the specific entropy at the turbine inlet. The subscripts "S,th" and "T,in" indicate static conditions in the throat section and total conditions in the expander inlet section (i.e. total inlet pressure $p_{\mathrm{T} \text {,in }}$ and total temperature $T_{\mathrm{T}, \mathrm{in}}$ ), respectively. The enthalpy and the speed of sound are named $h$ and $c$. The variables $\dot{m}, \rho$ and $A_{\text {th }}$ are the mass flow rate through the 
nozzle, the density and the flow passage area. The throat passage area is a fixed parameter obtained from the design calculation. Equation 2 relates to the mass flow rate and the turbine inlet conditions at part-load. The off-design isentropic efficiency is predicted with the correlation proposed by Schobeiri [30].

The recuperator is modeled by the counter-current connection of 1D ThermoPower modules, much as the once-through boiler, see Figure 4. The heat transfer on the vapor side dominates. Therefore, the overall heat transfer coefficient is taken equal to that at the interface between the organic vapor and the metal wall. The overall heat transfer in off-design conditions and the pressure drops are modeled as for the once-through boiler.

The condenser is trivially modeled as a fixed pressure component. This assumption is justified considering the large availability of sea-water. The cooling circuit can thus be controlled in such a way that the condenser pressure is nearly constant. For simplicity, the condensate is assumed to leave the component in saturated conditions (no subcooling) with no pressure losses. The pump model is based on a head-volume flow curve derived by fitting the data of an existing centrifugal pump designed for similar volumetric flows and heads. The curve, given as a function of $\phi=\dot{m} / \rho \cdot \rho_{\text {des }} / \dot{m}_{\text {des }}$ and the rotation speed of the shaft $N$, is expressed as

$$
H=H_{\mathrm{des}} \cdot\left(b_{1}+b_{2} e^{\phi}\right) \cdot\left(\frac{N}{N_{\mathrm{des}}}\right)^{2},
$$

where $H$ is the head, $b_{1}=2.462$, and $b_{2}=-0.538$. The exponential functional form is selected in order to result in a monotonic relation. This formulation increases the model robustness compared to polynomial expressions. The isentropic efficiency of the pump is expressed as a function of the coefficient $F=\phi \cdot N_{\text {des }} / N$, using the methodology proposed by Veres [36]. 5 The off-design electric efficiency of the ORC generator is calculated similarly to the gas turbine generator. The electro-mechanic efficiency of the pump motor is evaluated by assuming a quadratic dependency on the ratio between the actual load and its nominal value. Figure 3 shows also the ORC control system, consisting of a proportional-integral (PI) controller. This component adjusts the speed of the pump to maintain the temperature at the inlet of the expander (TIT in Figure 3) equal to the design-point value (SP_TIT in Figure 3). This strategy, currently used in ORC turbogenerators [34], ensures safe activities by tracking the hottest fluid temperature of the thermodynamic cycle.

3 The model of the ORC system is made of software objects acquired from a library that was developed to model a $150 \mathrm{~kW}$ ORC turbogenerator using toluene as the working fluid. This was 
1 successfully validated for dynamic operation against experimental data [34]. The model of the 2 bottoming cycle unit is, therefore, deemed reliable, considering the similarity of the application at hand with the one presented in the cited reference.

\section{3.4. The wind farm}

Figure 5 reports the wind speed probability curve. The data are representative for the North Sea. A wind speed of $9 \mathrm{~m} \cdot \mathrm{s}^{-1}$ is chosen as average wind speed, since it has the highest probability of occurrence, equal to 0.35 , as shown in Figure 5. The turbulent wind is created by the IEC Turbulence Simulator in the WAsP Engineering model using the Mann model [37]. The turbulence intensity, $I_{t}$, is calculated using the normal turbulence model [38], as following

$$
I_{t}=\frac{I_{\mathrm{ref}}\left(0.75 \cdot V+5.6\left[\mathrm{~ms}^{-1}\right]\right)}{V}
$$

5 where $V$ is the wind speed velocity in $\mathrm{m} \cdot \mathrm{s}^{-1}$ and $I_{\text {ref }}=0.14$ is the expected value of the turbulence intensity at a wind speed of $15 \mathrm{~m} \cdot \mathrm{s}^{-1}$ for medium turbulence characteristics [38]. Hence, at $9 \mathrm{~m} \cdot \mathrm{s}^{-1}, I_{t}$ results equal to 0.19 .

8 Considering a NREL $5 \mathrm{MW}$ wind turbine (as described in section 2), the wind turbine power 9 production is calculated by the aeroelastic code Flex5 [39]. This code is widely used in the inio dustry to model the dynamic behavior of the wind turbine and monopile foundation. The aero1 dynamic loads on the blades are calculated by the unsteady blade-element-momentum (BEM) 2 method.

${ }_{13}$ The wind instantaneous speed and the power production of the wind generator are obtained for 14 one hour, considering a time step equal to $0.02 \mathrm{~s}$ and processed as described in section 4.2.

\subsection{Economic evaluation}

The economic evaluations are based on the net present value (NPV) method. The NPV is calculated considering the equipment lifespan $n$, the interest factor $q$, the total investment cost $I_{T O T}$ and the annual income $R_{i}$. Moreover, $M_{a}$ is a non-dimensional factor that accounts for operating and maintenance costs.

$$
N P V=\sum_{i=1}^{n} M_{a} \frac{R_{i}}{(1+q)^{i}}-I_{T O T}
$$


The major sources of annual incomes are associated with the fuel savings and with the avoided $\mathrm{CO}_{2}$ taxes, respectively named $R_{n g}$ and $R_{\mathrm{CO} 2}$, evaluated as

$$
\begin{gathered}
R_{n g}=c_{n g} v_{s t} \Delta \dot{m}_{n g} h_{u}, \\
R_{\mathrm{CO} 2}=c_{\mathrm{CO} 2} \Delta \dot{m}_{\mathrm{CO} 2} h_{u},
\end{gathered}
$$

1 where $c_{n g}$ is the price of natural gas, $v_{s t}$ is the fuel specific volume calculated at $15{ }^{\circ} \mathrm{C}$ and $1.013 \mathrm{bar}, \Delta \dot{m}_{n g}$ is the fuel saving and $h_{u}$ represents the capacity factor in $\mathrm{h} / \mathrm{yr}$. In eq. (7), $c_{C O 2}$ represents the carbon dioxide tax and $\Delta \dot{m}_{\mathrm{CO} 2}$ is the avoided $\mathrm{CO}_{2}$ emission.

\section{Results and discussion}

Section 4.1 presents the simulation results used to identify the maximum wind power installable on-board. The selection criteria are the standards specified for offshore stand-alone electric grids. Sections 4.2 and 4.3 analyze the plant flexibility and the energy savings during the wind power fluctuations.

\subsection{The maximum allowable wind power}

The electric power required by the oil and gas platform is assumed constant and equal to $30 \mathrm{MW}$. This nominal demand is a reasonable figure for offshore facilities in the North Sea [40]. The power system on board (three combined cycle units) has a total installed capacity of $64 \mathrm{MW}$. Two combined cycle units run at a time covering $50 \%$ of the load each. The third unit is on stand-by. This operational strategy is commonly adopted in offshore power stations in order to enhance the system reliability and ensure the necessary reserve power for peak loads. The sudden loss of wind power is the worst possible scenario the plant has to withstand without compromising the functionality of the power system. The scenario implies that the wind turbines provide their maximum power output and the two combined cycle plants supply the remaining power until $200 \mathrm{~s}$, when, in $1 \mathrm{~s}$, the wind power production drops to zero. As a consequence, the GT+ORCs have to increase the load to match the total power demand and stabilize the grid frequency. The maximum absolute frequency change has to be lower than $5 \%$, as imposed by the NORSOK standard [41]. This dynamic metric is thus used to identify the maximum wind power $\dot{P}_{n}$ installable on board.

The possible scenarios are: 
- case 1: one wind turbine installed $\left(\dot{P}_{n}=5 \mathrm{MW}\right)$,

- case 2: two wind turbines installed $\left(\dot{P}_{n}=10 \mathrm{MW}\right)$,

- case 3: three wind turbines installed $\left(\dot{P}_{n}=15 \mathrm{MW}\right)$.

Figure 6 shows the frequency dynamics for the three test cases. The plot reports also the maximum allowable undershooting (red dotted line). All curves exhibit an undershooting, caused by the increased load demand. Figure 6 demonstrates that case 3 is not feasible as the frequency exceeds the prescribed threshold. Therefore, the integration of three wind turbines is not acceptable for the stability of the grid. The second dynamic metric used to compare the three cases is the rise time. This quantity is defined as the time required for the frequency to return back to $99 \%$ of the value at steady-state $(50 \mathrm{~Hz})$. Case 1 and 2 present faster responses than case 3 , with a rise time of $2 \mathrm{~s}$ and $8 \mathrm{~s}$, respectively. Case 3 presents a rise time of $11 \mathrm{~s}$, as visible in Figure 6. Two wind turbines are installable in nominal conditions. They can supply one third of the electric load on the platform (30 MW) without compromising the stability of the electric grid. Figure 7 shows the trend of the temperature at the inlet of the ORC expander during the loss of the wind power. This variable is of paramount importance, being closely related to the maximum temperature reached by the ORC working fluid. Its thermal stability is a major concern in the design of ORC systems. The fluid decomposition can compromise the integrity and the performance of the components. The plot demonstrates that the peak value of the temperature in case 2 , obtained after $460 \mathrm{~s}$, is equal to $314.9^{\circ} \mathrm{C}$. This value is acceptable for the thermal stability of benzene. Andersen et al. [23] demonstrated that the decomposition is negligible for operating temperatures lower than $315^{\circ} \mathrm{C}$.

\subsection{The plant flexibility}

This section aims at evaluating the capability of the power system to rapidly adapt to an electric grid with varying production of wind power. Given the results presented in Section 4.1, two wind turbines are connected to the grid. Figure 8 shows the production data of the two generators, named WT1 and WT2. The time range is equal to $200 \mathrm{~s}$. This time is long enough to evaluate the dynamics of the integrated system. The values given in the plot are derived from the data computed as described in Section 3.4. The data collected for the first 30 minutes are used to reproduce the WT1 wind fluctuations. The data collected for the remaining time 
are used for the WT2. The production data are integrated in the plant model using a time-step of $1 \mathrm{~s}$. The dynamics of the power system is also assessed for the three gas turbines without waste heat recovery unit. This allows to quantify the impact of the ORC units on the dynamic flexibility of the system. The two plant configurations under investigation are:

- configuration A: the wind farm is coupled to three combined cycle units,

- configuration B: the wind farm is integrated with three gas turbines.

In both cases, two units run at the same time covering $50 \%$ of the required power each. The third engine is on stand-by.

The power demand on board is constant and equal to $30 \mathrm{MW}$ in the two configurations. Figure 9(a) shows the power produced by the five electric generators connected to the grid (configuration A). The gas turbines and the ORC modules produce $62 \%$ and $18 \%$ of the total demand. The wind mill supplies the remaining $20 \%$. Figure $9(\mathrm{~b})$ shows that the gas turbines have to cover around $80 \%$ of the total required power as for configuration B.

Figure 10 shows the frequency trends of the two configurations as a function of time. The presence of the organic Rankine cycle units reduces the small frequency oscillations compared to the use of two gas turbines alone. On the other hand, the maximum frequency variations are higher in case of ORCs installation.

Figure 11 reports the mechanical power produced by the topper and bottomer units, e.g., $P_{\mathrm{m}, \mathrm{GT}} \_A$ and $P_{\mathrm{m}, \mathrm{ORC}}$, considering configuration $\mathrm{A}$, and the mechanical power produced by the gas turbine $P_{\mathrm{m}, \mathrm{GT}} B$ considering configuration $\mathrm{B}$. The reported data refer to one combined cycle (GT and ORC) in configuration A and to one gas turbine in configuration B.

The plot pinpoints that the fluctuations of wind power do not influence the power produced by the ORC turbine. The maximum $P_{\mathrm{m}, \mathrm{ORC}}$ variation is lower than $0.2 \mathrm{MW}$. This trend is due to the inertia of the heat transfer equipment included in the ORC turbogenerator. The GTs are thus responsible for satisfying the load demand and cope with the wind power variability.

Figure 12 shows the variation of the mechanical power produced by the gas turbines with respect to the steady-state value for configuration A and B. In Figure 12, the area under the red and black curves, representative of configuration A and B respectively, result equal to $176 \mathrm{MJ}$ and $191 \mathrm{MJ}$. These values are related with the kinetic energy stored into the rotating masses. The use of the ORC units enables to reduce the variation of the mechanical power produced 
by the gas turbines, but it reduces the storable kinetic energy. This smooths the dynamics of the fuel injection valve and reduces the smallest oscillations of the frequency. Note that the manufacturer designed the control system for the operations of the sole gas turbines. The implementation of the ORC turbogenerators may require a further tuning of the controller, thus improving the system dynamics. This is, however, beyond the scope of the present work. All the presented results suggest that the ORC systems enable to decrease the amplitude of the valve regulation. The response of gas turbines in configuration B results quicker to load variations than in configuration A. Therefore, the integrated system in configuration A is less capable to following the wind fluctuationsthan the system in configuration B.

\subsection{Fuel savings and emission reduction}

Figure 13 shows the fuel consumption and the $\mathrm{CO}_{2}$ emissions of the two power systems (configuration A and B). The plot demonstrates that the implementation of the waste heat recovery systems can reduce the fuel consumption and $\mathrm{CO}_{2}$ emissions by more than $15 \%$. Namely, the use of ORC units (configuration A) enables to save more than $60 \mathrm{~kg}$ of fuel and $170 \mathrm{~kg}$ of $\mathrm{CO}_{2}$ in a time period of $200 \mathrm{~s}$.

An economic assessment is possible based on the fuel and $\mathrm{CO}_{2}$ savings. The NPV method (described in section 3.5) is used to assess the economic feasibility of the waste heat recovery units and wind mill. Based on information provided by the platform operator, reasonable figures for the discount rate and the life-time of the investment are $6 \%$ and 20 years. The operating and maintenance costs are also accounted with an appropriate coefficient $\left(M_{a}\right.$ in section 3.5 set equal 0.9). The two sources of annual incomes are associated with the fuel savings and with the avoided $\mathrm{CO}_{2}$ taxes. A fuel price of $0.09 \$ \cdot \mathrm{Sm}^{-3}$ and a carbon dioxide tax of $55.9 \$ \cdot \mathrm{t}^{-1}[2]$ is assumed. The yearly demand of electricity is calculated assuming a constant duty of $30 \mathrm{MW}$ and a capacity factor of 7000 hours per year. The investment cost of the wind turbines per unit of power is equal to $5 \$ / \mathrm{W}[42]$, while a specific price of $3 \$ / \mathrm{W}$ is considered for the ORC units.

The evaluated NPVs are equal to $173 \mathrm{M} \$$ and $91.5 \mathrm{M} \$$ for configuration A and B. This preliminary calculation suggests that the installation of the wind mill and waste heat recovery system is economically feasible. 


\section{Conclusions}

This paper presents a dynamic study of a novel offshore power system for oil and gas platforms. More in detail, the power system on board consists of three gas turbines each one equipped with an organic Rankine cycle turbogenerator. A wind mill is also connected to the stand-alone electric grid to reduce the fuel consumption and pollutants. The platform considered as case study has a nominal electric power require of $30 \mathrm{MW}$, and it is located in the North Sea. A dynamic model of the power system is developed in the programming language Modelica using component models from validated libraries. The simulations suggest that the wind mill should cover not more than one third of the power consumption in nominal conditions. This can be accomplished by using two wind turbines with a design capacity of $5 \mathrm{MW}$ each. The frequency tolerance prescribed for offshore grids is not respected with a higher number of wind turbines. The use of the organic Rankine cycle units reduces the frequency fluctuations caused by the variability of the wind production, compared to the installation of the gas turbines alone. Conversely, the waste heat recovery system makes the plant slower due to inertia of the heat transfer equipment, due to the lower mechanical power available at the shaft. The difference between the kinetic energy stored by the rotating masses results equal to $15 \mathrm{MJ}$ in the analyzed time interval.

It is advisable to obtain new control systems to tackle this issue and to cope with the extreme need for reliability. Future work will thus focus on the improvement of the gas turbine control system using model-based regulators, e.g., the model predictive control. Moreover, the use of an electric storage system could be a feasible solution to reduce the grid instability and to improve the efficiency of the overall integrated system.

\section{References}

[1] Adam Barker and Carys Jones. A critique of the performance of eia within the offshore oil and gas sector. Environmental Impact Assessment Review, 43:31-39, 2013.

[2] Ministry of the Environment. The Government is following up on the Climate Agreement, October 2012.

[3] Iñigo Martínez de Alegría, Jose Luis Martín, Iñigo Kortabarria, Jon Andreu, and Pedro Ibañez Ereño. Transmission alternatives for offshore electrical power. Renewable and Sustainable Energy Reviews, 13(5):1027-1038, 2009.

[4] Temesgen M. Haileselassie, Marta Molinas, Tore Undeland, et al. Multi-terminal VSC-HVDC system for integration of offshore wind farms and green electrification of platforms in the North Sea. 2008. 
[5] L. Stendius and P. Jones. The challenges of offshore power system construction-bringing power successfully to Troll A, one of the worlds largest oil and gas platform. March 2006.

[6] Jens Hetland, Hanne Marie Kvamsdal, Geir Haugen, Fredrik Major, Vemund Kårstad, and Göran Tjellander.

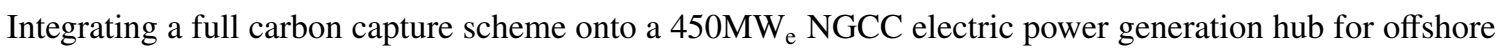
operations: Presenting the Sevan GTW concept. Applied Energy, 86(11):2298-2307, 2009.

[7] Henriette Undrum, Olav Bolland, and Eivind Aarebrot. Economical assessment of natural gas fired combined cycle power plant with co2 capture and sequestration. In Fifth International Conference on Greenhouse Gas Control Technologies, Cairns, Australia, 2000.

[8] Pål Kloster. Energy optimization on offshore installations with emphasis on offshore combined cycle plants. 1999.

[9] O. Bolland, .M Forde, and B. Hånde. Air bottoming cycle: use of gas turbine waste heat for power generation. Journal of engineering for gas turbines and power, 118:359-368, 1996.

[10] Leonardo Pierobon and Fredrik Haglind. Design and optimization of air bottoming cycles for waste heat recovery in off-shore platforms. Applied Energy, 118:156-165, 2014.

[11] Alberto Benato, Leonardo Pierobon, Fredrik Haglind, and Anna Stoppato. Dynamic performance of a combined gas turbine and air bottoming cycle plant for off-shore applications. In ASME 2014 12th Biennial Conference on Engineering Systems Design and Analysis, pages V002T09A003-V002T09A003. American Society of Mechanical Engineers, 2014.

[12] Leonardo Pierobon, Tuong-Van Nguyen, Ulrik Larsen, Fredrik Haglind, and Brian Elmegaard. Multiobjective optimization of organic Rankine cycles for waste heat recovery: Application in an offshore platform. Energy, 58:538-549, 2013.

[13] R.K. Bhargava, M. Bianchi, L. Branchini, A. De Pascale, F. Melino, A. Peretto, and E. Valentini. Thermoeconomic evaluation of orc system in off-shore applications. In ASME Turbo Expo 2014: Turbine Technical Conference and Exposition. American Society of Mechanical Engineers, 2014.

[14] Leonardo Pierobon, Rambabu Kandepu, and Fredrik Haglind. Waste heat recovery for offshore applications. In ASME 2012 International Mechanical Engineering Congress and Exposition, pages 503-512. American Society of Mechanical Engineers, 2012.

[15] Hywind by StatoilHydro. The world's first full scale floating wind turbine, September 2009.

[16] LORC Knoledge. Bard Offshore 1 Offshore Wind Farm, 2012.

[17] Atle Rygg Årdal, Tore Undeland, and Kamran Sharifabadi. Voltage and frequency control in offshore wind turbines connected to isolated oil platform power systems. Energy Procedia, 24(0):229-236, 2012. Selected papers from Deep Sea Offshore Wind R\&amp;D Conference, Trondheim, Norway, 19-20 January 2012.

[18] Jorun I Marvik, Eirik V Øyslebø, and Magnus Korpås. Electrification of offshore petroleum installations with offshore wind integration. Renewable Energy, 50:558-564, 2013.

[19] Wei He, Gunnar Jacobsen, Tiit Anderson, Freydar Olsen, Tor D Hanson, Magnus Korpås, Trond Toftevaag, Jarle Eek, Kjetil Uhlen, and Emil Johansson. The potential of integrating wind power with offshore oil and gas platforms. Wind Engineering, 34(2):125-138, 2010.

[20] Jason Mark Jonkman, Sandy Butterfield, Walter Musial, and George Scott. Definition of a 5-MW reference 
wind turbine for offshore system development. National Renewable Energy Laboratory Golden, Golden, Colorado, USA, 2009.

[21] Simon-Philippe Breton and Geir Moe. Status, plans and technologies for offshore wind turbines in europe and north america. Renewable Energy, 34(3):646-654, 2009.

[22] Piero Colonna, Emiliano Casati, Carsten Trapp, Tiemo Mathijssen, Jaakko Larjola, Teemu Turunen-Saaresti, and Antti Uusitalo. Organic Rankine Cycle Power Systems: From the Concept to Current Technology, Applications, and an Outlook to the Future. Journal of Engineering for Gas Turbines and Power, 137(10):1-19, 2015.

[23] Wendy C Andersen and Thomas J Bruno. Rapid screening of fluids for chemical stability in organic rankine cycle applications. Industrial $\mathcal{F}$ engineering chemistry research, 44(15):5560-5566, 2005.

[24] Francesco Casella and Alberto Leva. Modelling of thermo-hydraulic power generation processes using modelica. Mathematical and Computer Modelling of Dynamical Systems, 12(1):19-33, 2006.

[25] F. Casella, T. Mathijssen, P. Colonna, and J. van Buijtenen. Dynamic modeling of ORC power systems. Journal of Engineering for Gas Turbines and Power, 135:1-12, 2012.

[26] Joachim Kurzke. Component map collection 2, Compressor and turbine maps for gas turbine performance computer programs. www.gasturb.de/ [accessed: 19/09/2013]. Germany, 2004.

[27] F. Carchedi and G. R. Wood. Design and development of a 12:1 pressure ratio compressor for the Ruston 6-MW gas turbine. Journal for Engineering for Power, 104:823-831, 1982.

[28] Joachim Kurzke. How to create a performance model of a gas turbine from a limited amount of information. ASME paper GT2005-68537, pages 145-153, June 2005.

[29] A. Stodola. Dampf- und Gasturbinen: Mit einem Anhang über die Aussichten der Wärmekraftmaschinen. Springer Berlin, Berlin, Germany, 1922. ISBN: 7352997563.

[30] Meinhard Schobeiri. Turbomachinery flow physics and dynamic performance. Springer Berlin, Berlin, Germany, 2005. ISBN: 9783540223689.

[31] S.M. Camporeale, B. Fortunato, and A. Dumas. Dynamic modelling of recuperative gas turbines. Proceedings of the Institution of Mechanical Engineers, Part A: Journal of Power and Energy, 214(3):213-225, 2000.

[32] Fredrik Haglind and Brian Elmegaard. Methodologies for predicting the part-load performance of aeroderivative gas turbines. Energy, 34(10):1484-1492, 2009.

[33] L. Pierobon, K. Iyengar, P. Breuhaus, R. Kandepu, M. Hana, and F. Haglind. Dynamic performance of power generation systems for off-shore oil and gas platforms. In Proceedings of ASME Turbo Expo 2014, 2014.

[34] Francesco Casella, Tiemo Mathijssen, Piero Colonna, and Jos van Buijtenen. Dynamic modeling of organic rankine cycle power systems. Journal of Engineering for Gas Turbines and Power, 135(4):042310, 2013.

[35] Frank P. Incropera, David P. DeWitt, Theodore L. Bergman, and Adrienne S. Lavine. Fundamentals of Heat and Mass Transfer. John Wiley \& Sons, Inc., Jefferson City, United States of America, 6 edition, 2007. ISBN: 9780470501979.

[36] J. P. Veres. Centrifugal and axial pump design and off-design performance prediction. Technical report, NASA, Sunnyvale, United States of America, 1994. Technical Memorandum 106745. 
1 [37] Jakob Mann. Wind field simulation. Probabilistic engineering mechanics, 13(4):269-282, 1998.

[38] International Electrotechnical Commission - IEC. International Standar. IEC 61400-1. Wind turbines. Part 1:Design Requirements, 2005.

4 [39] Stig Øye. Flex4 simulation of wind turbine dynamics. 1996.

5 [40] Tuong-Van Nguyen, Leonardo Pierobon, Brian Elmegaard, Fredrik Haglind, Peter Breuhaus, and Mari Voldsund. Exergetic assessment of energy systems on North Sea oil and gas platforms. Energy, 62(0):23-36, 2013.

8 [41] Norwegian Technology Centre. Electrical systems norsok standard e-001. Technical report, 2007.

9 [42] Douglas-Westwood. Offshore wind asessment for norway: Final report, 2010.

\section{Figures}

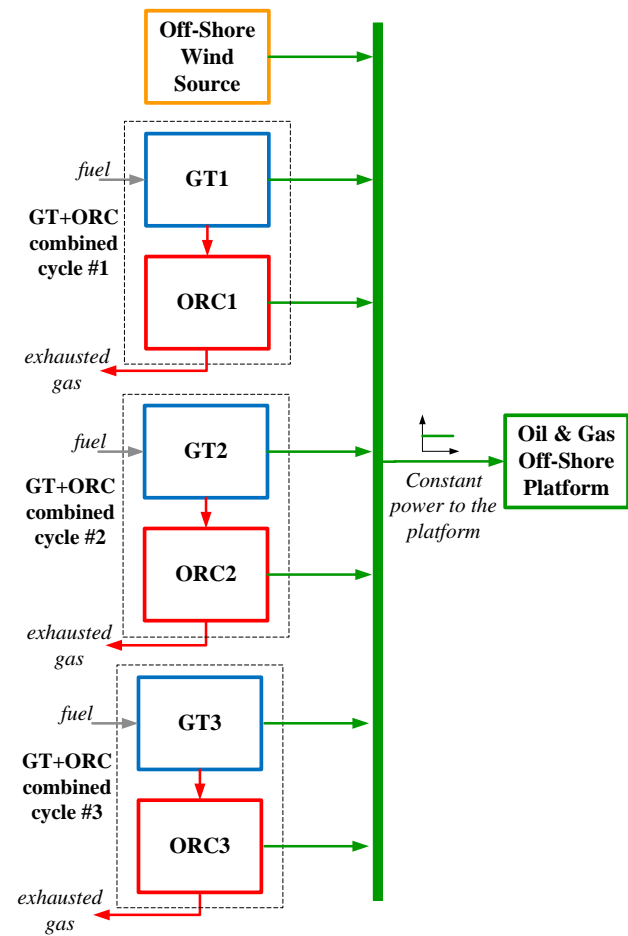

(a)

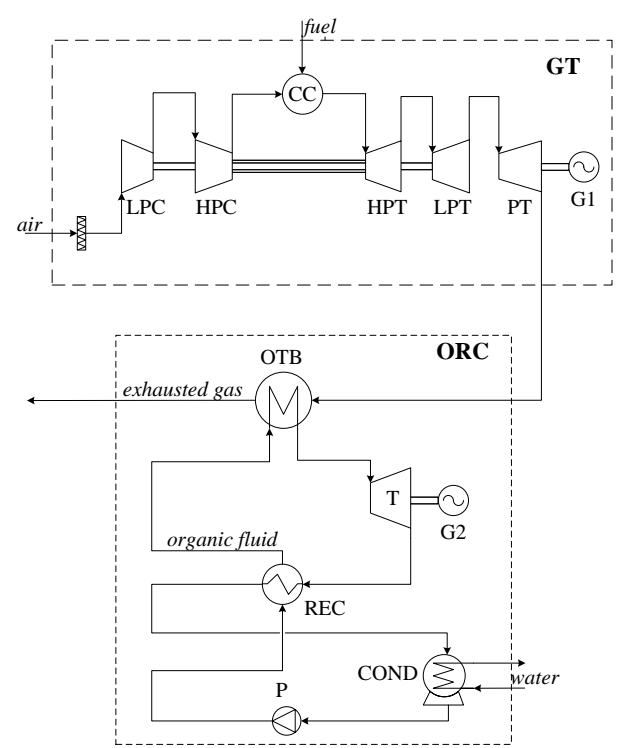

(b)

Figure 1: Layout of the power system considered as case study. Figure 1(a) Integration of gas turbines, organic Rankine cycle units and wind farm with the electric grid. 1(b) Combined cycle unit configuration. 


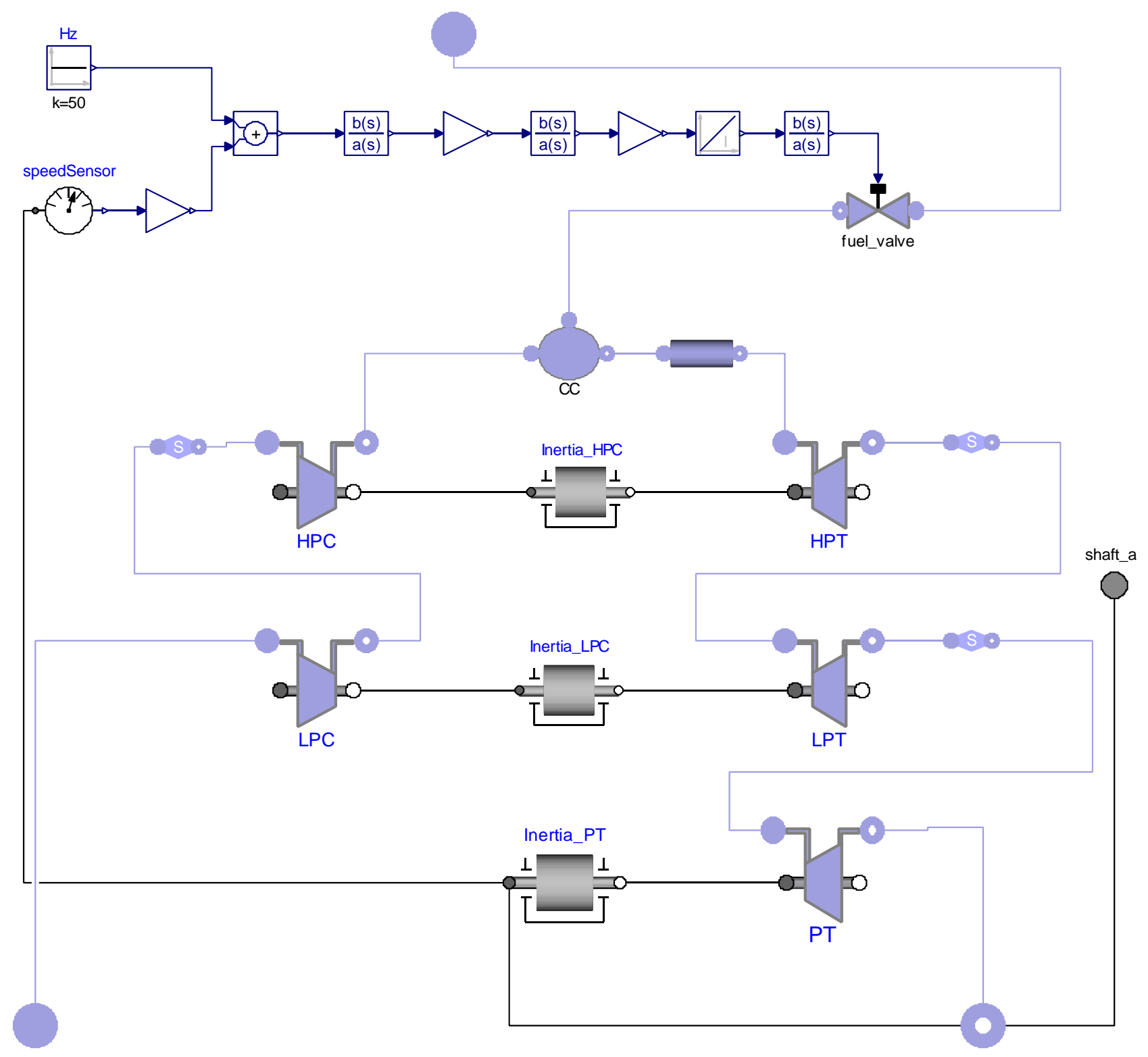

Figure 2: Object diagram of the gas turbine sub-system model. 


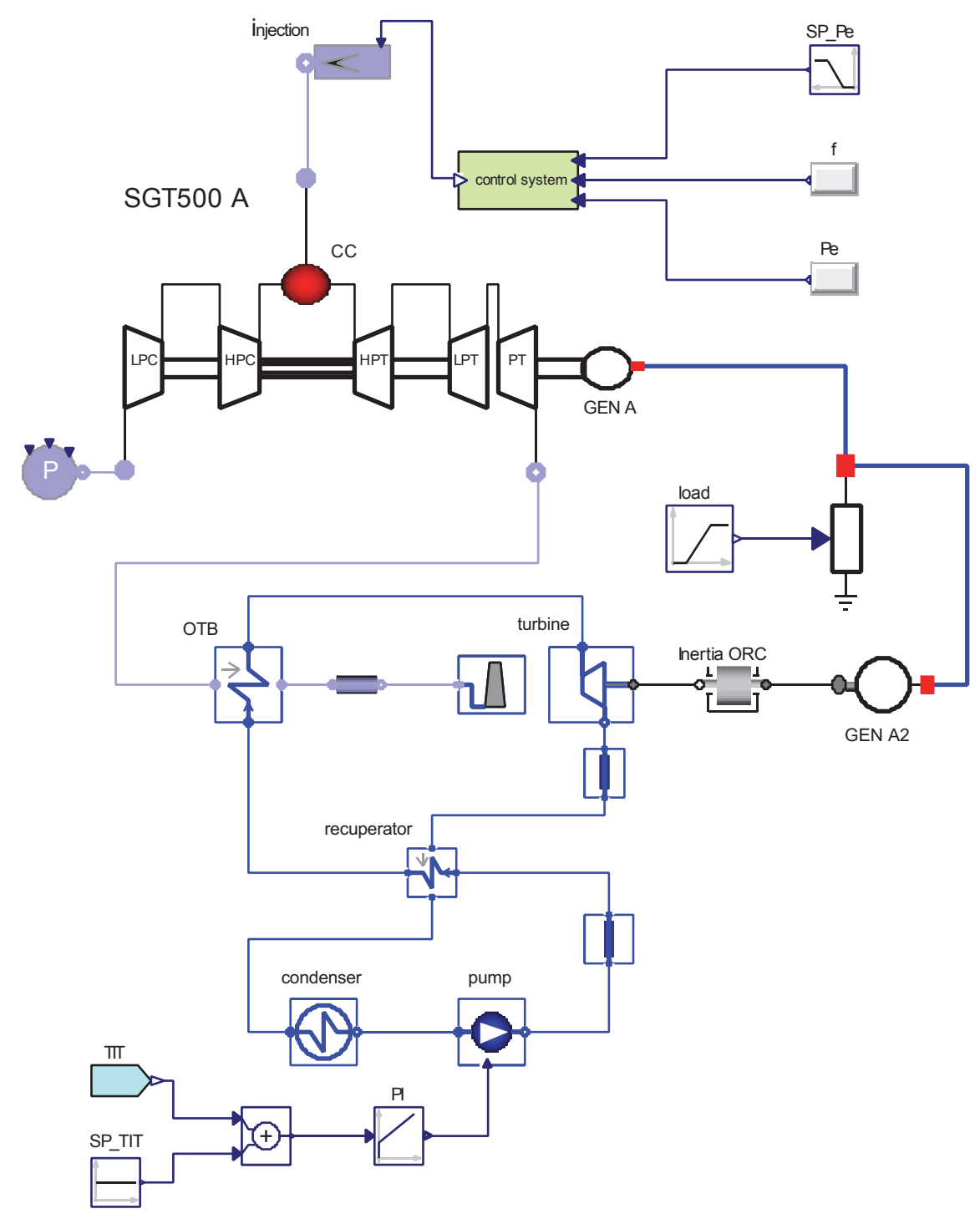

Figure 3: Object diagram of the combined cycle unit. 


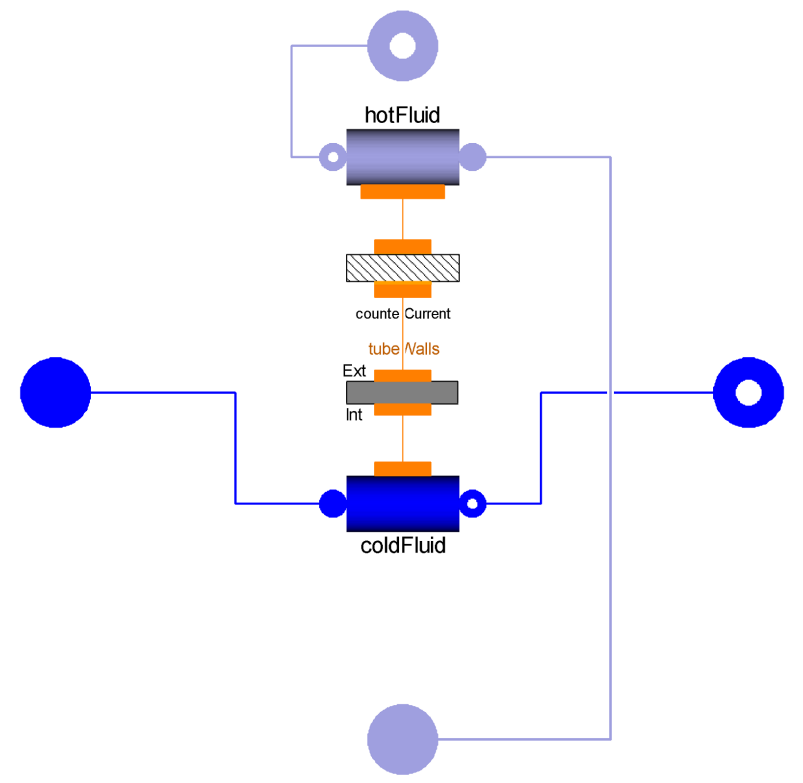

Figure 4: Modelica object diagram of the once-through heat exchanger model.

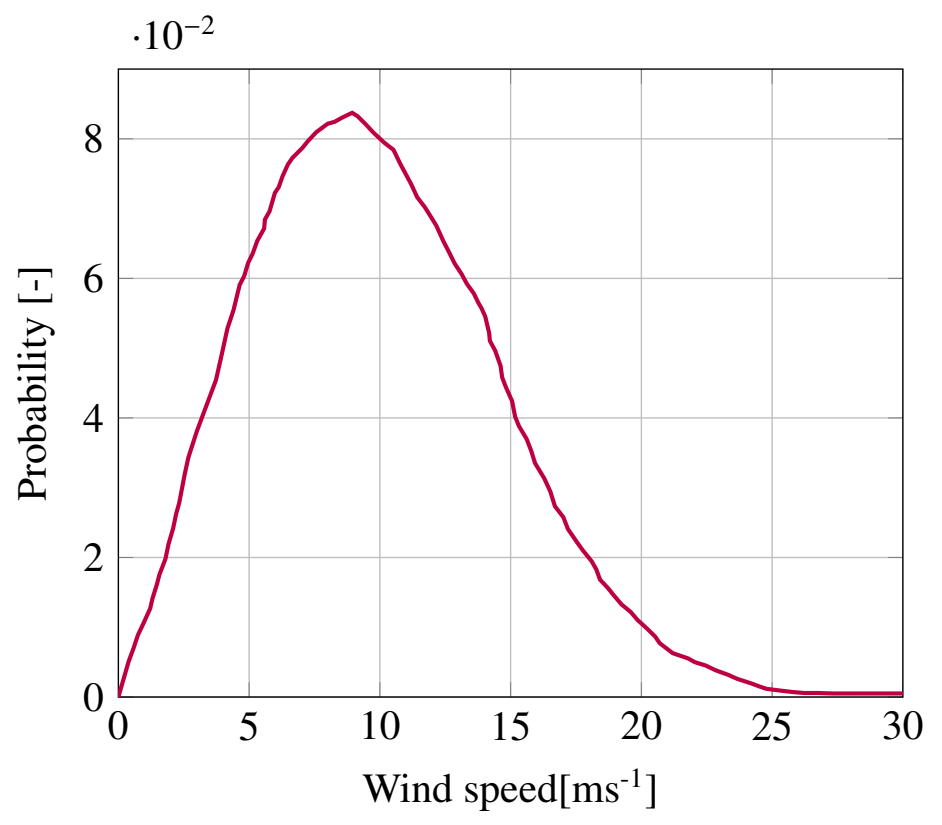

Figure 5: Probability of occurrence. 


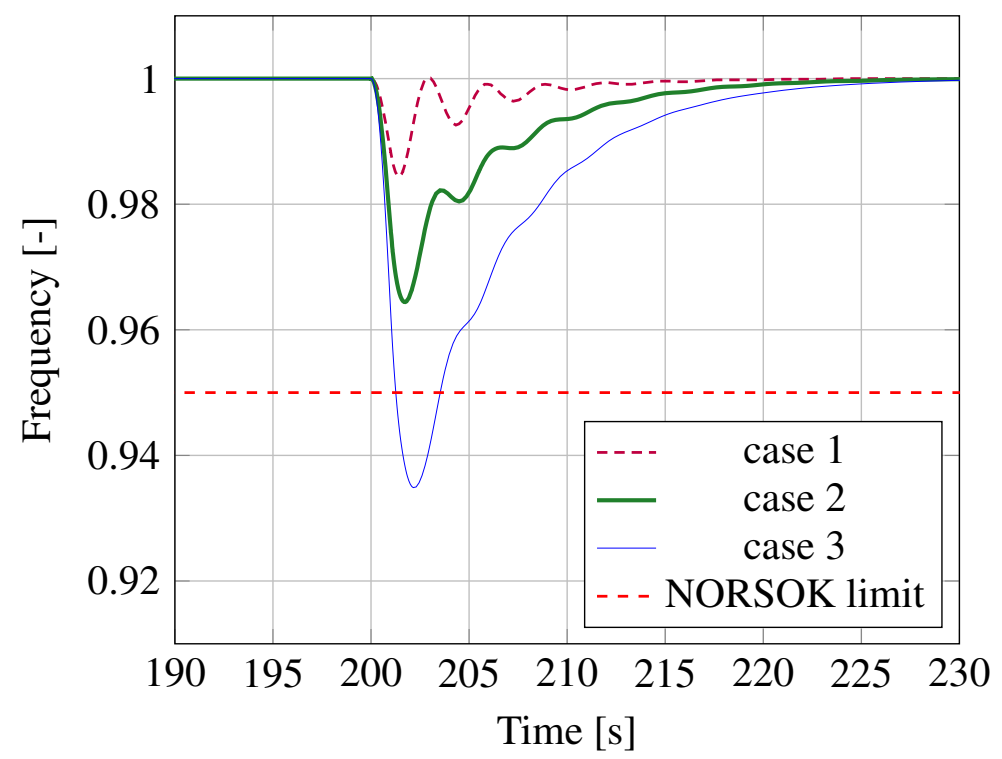

Figure 6: Frequency variations for the analyzed scenarios.

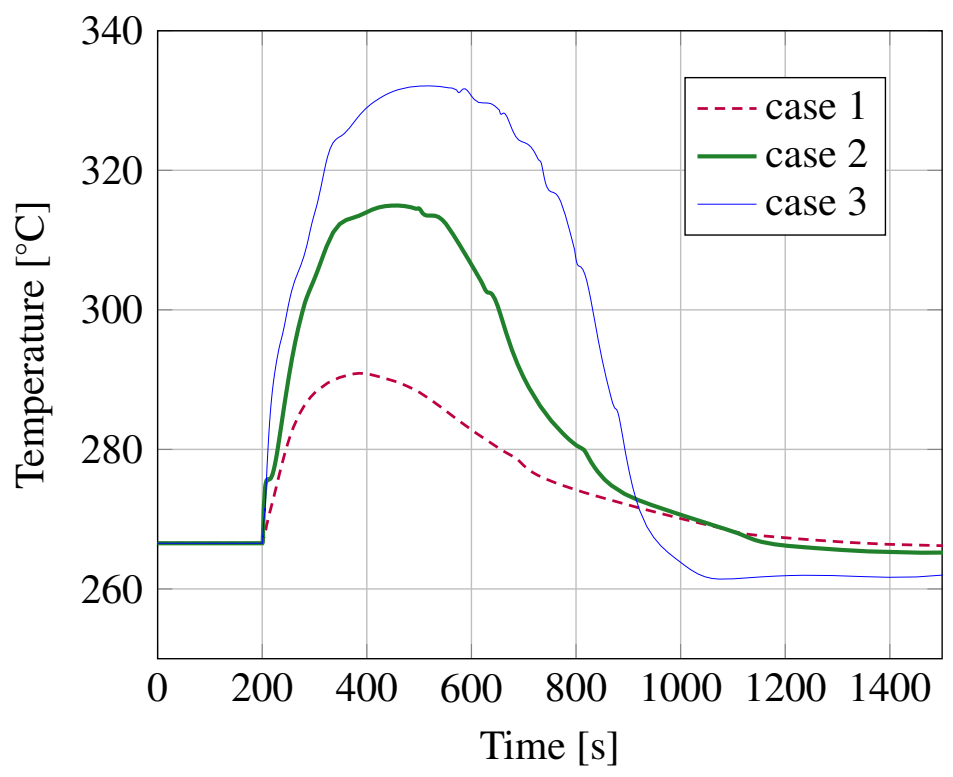

Figure 7: Organic Rankine cycle operating fluid maximum temperature for the analyzed scenarios. 


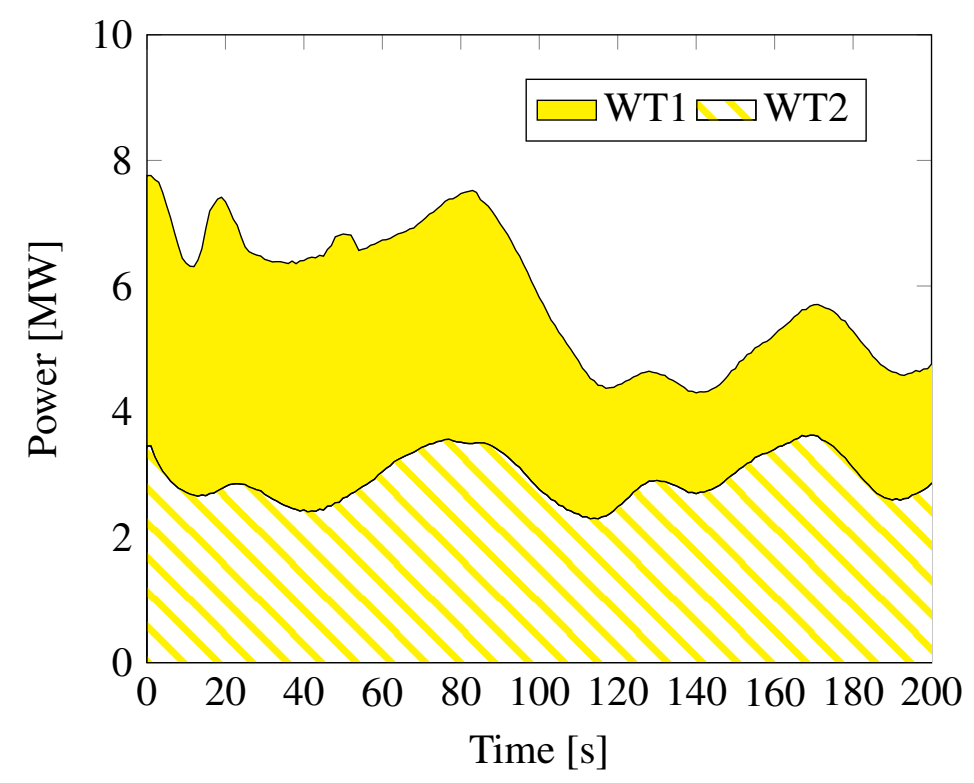

Figure 8: Electric power of the two wind turbines as a function of time.

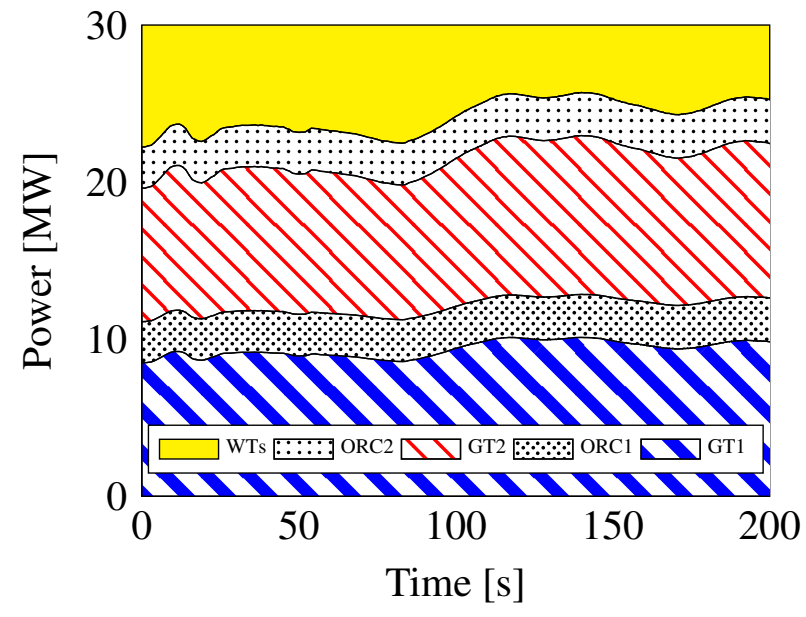

(a)

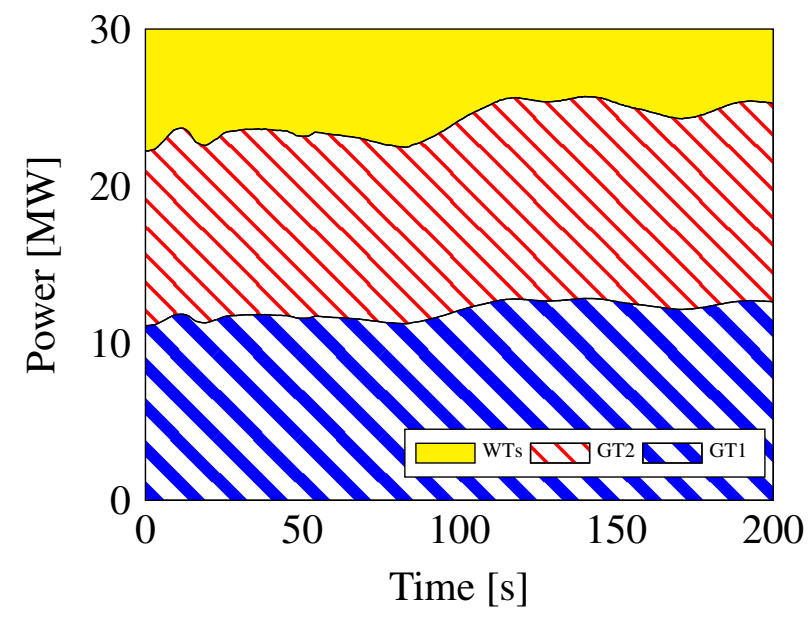

(b)

Figure 9: Power of the electric generators connected to the grid as a function of time. 9(a): two gas turbines, two organic Rankine cycle units and the wind mill. 9(b): two gas turbines and the wind mill 


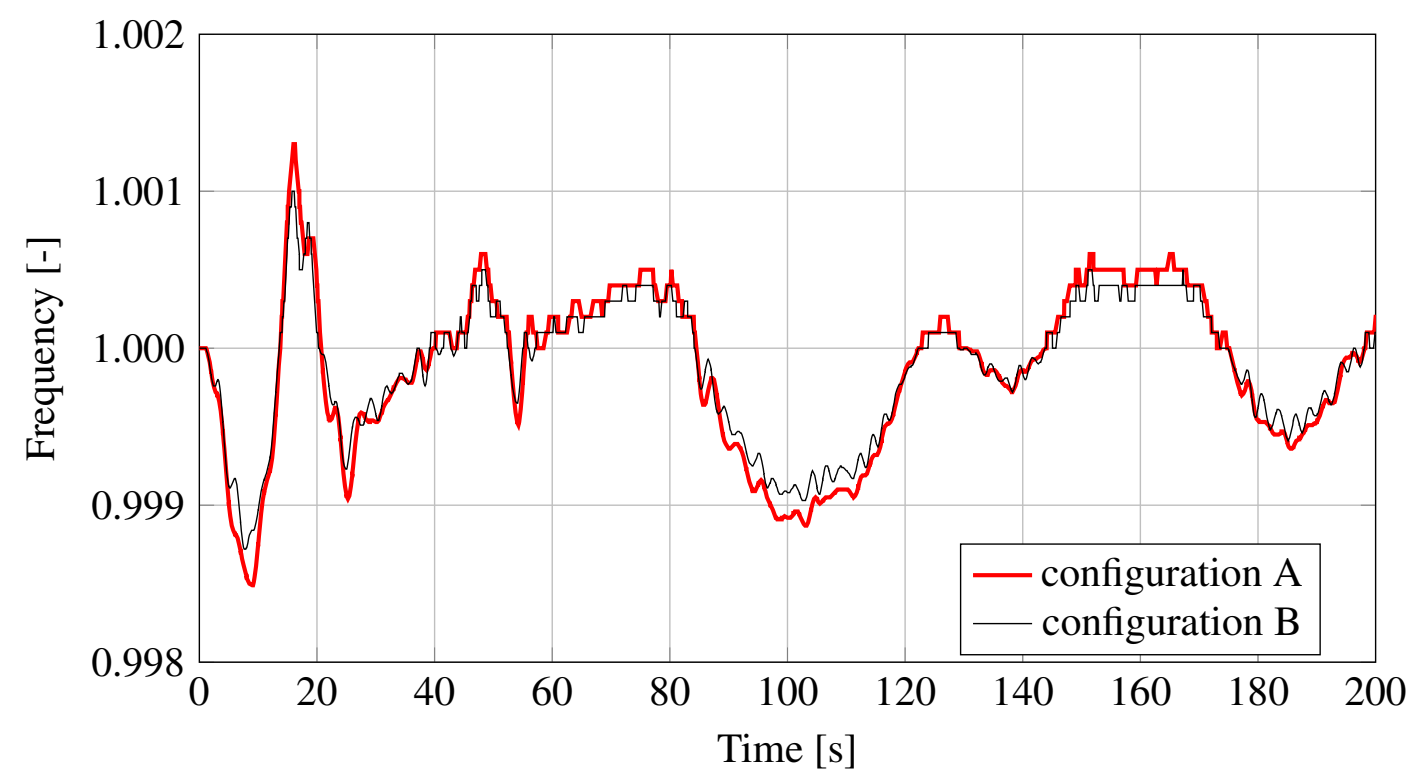

Figure 10: Frequency trends as a function of time. In configuration A, the gas turbines, the organic Rankine cycle units and the wind mill supply the electric grid. Conversely, configuration B entails the use of the gas turbines and the wind mill.

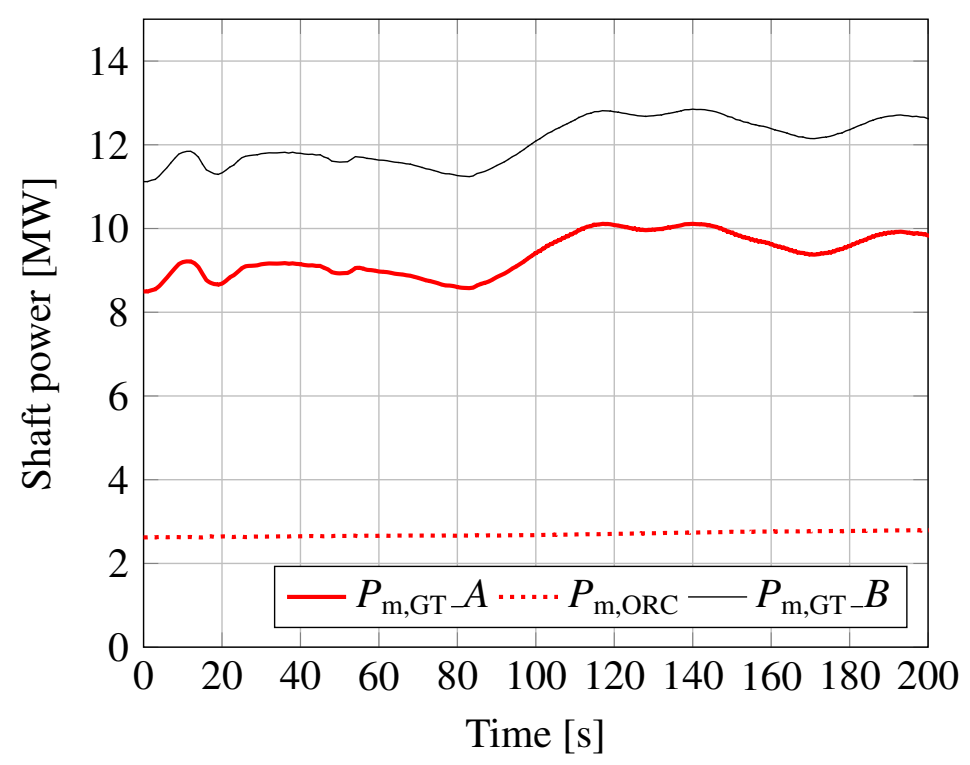

Figure 11: Gas turbine and organic Rankine cycle mechanical power as function of time in configuration A in comparison with gas turbine mechanical power in configuration B. 


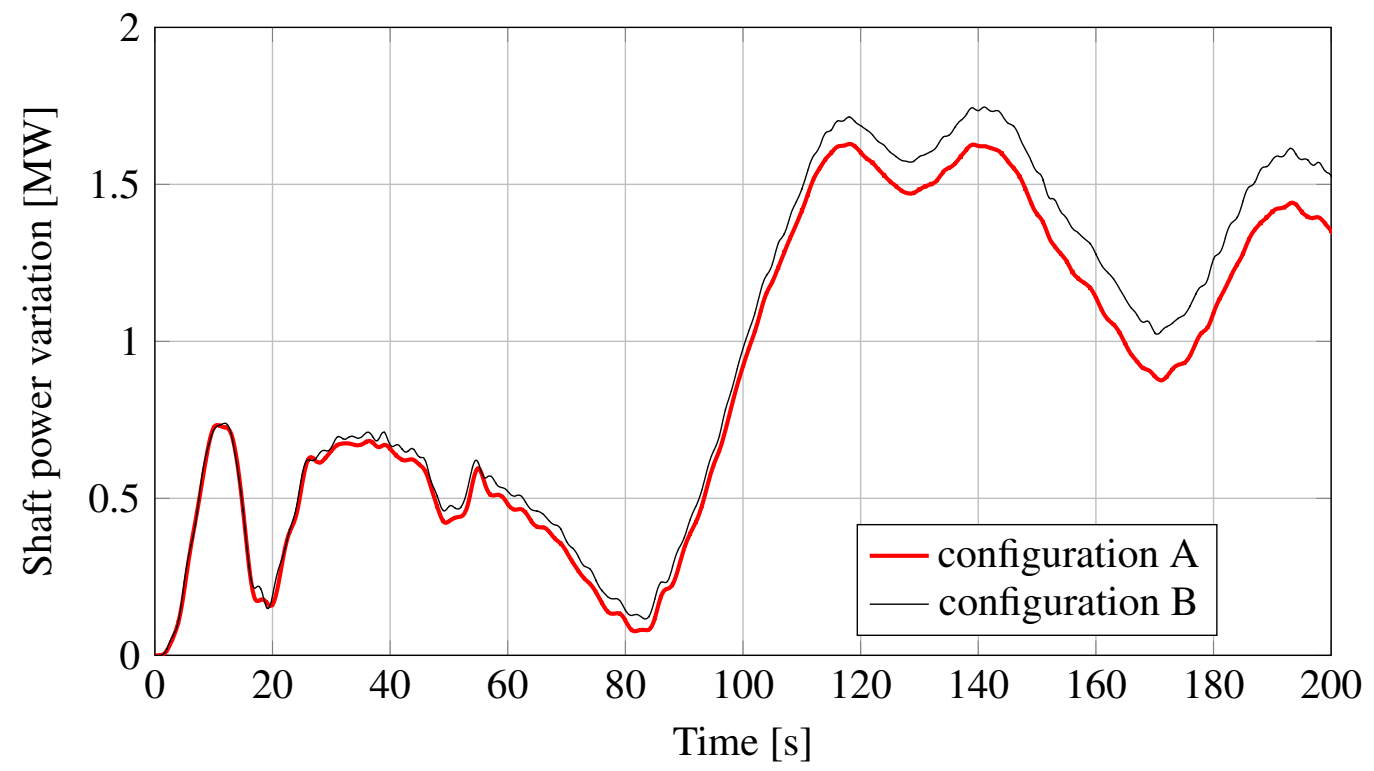

Figure 12: Variation of the mechanical power produced by a gas turbine with respect to the steady-state value for configuration $\mathrm{A}$ and $\mathrm{B}$.

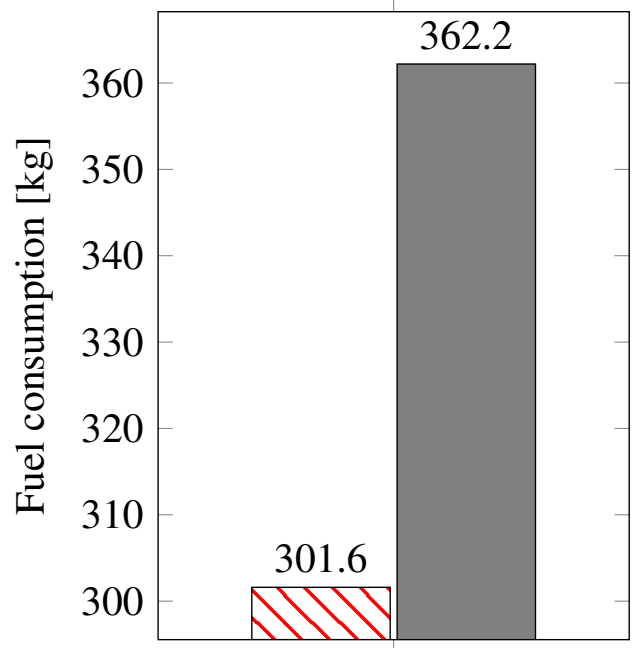

Fuel consumption

\section{QธConfiguration A $₫ \square$ Configuration B}

(a)

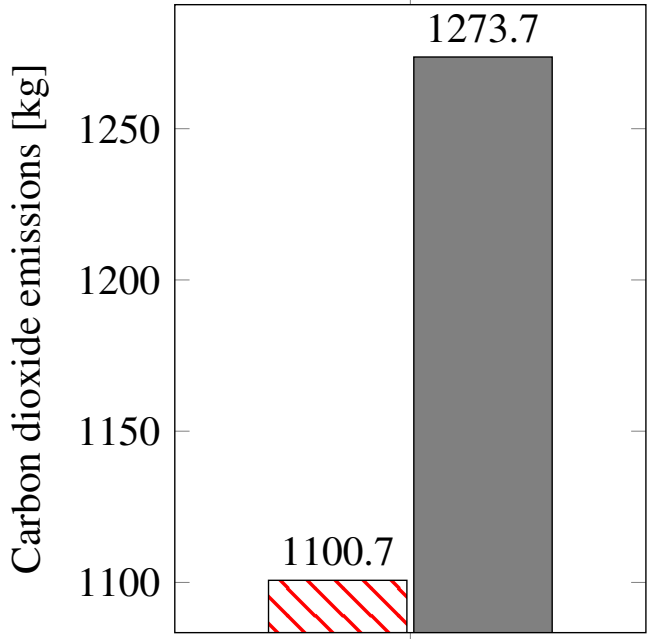

Carbon dioxide emissions

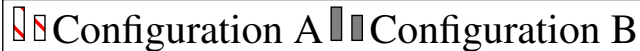

(b)

Figure 13: Fuel savings (13(a)) and carbon dioxide emissions (13(b)) of the gas turbines, the organic Rankine cycle units and the wind mill (configuration A) and for the gas turbines and the wind mill (configuration B). 
Table 1: Design specifications for the twin-spool gas turbine considered as topping unit.

\begin{tabular}{ll} 
Model & Siemens SGT-500 \\
\hline Turbine inlet temperature & $850{ }^{\circ} \mathrm{C}$ \\
Exhaust gas temperature & $379.2^{\circ} \mathrm{C}$ \\
Exhaust gas mass flow & $91.5 \mathrm{~kg} \cdot \mathrm{s}^{-1}$ \\
Electric power output & $16.5 \mathrm{MW}$ \\
Thermal efficiency & $31.3 \%$ \\
\hline
\end{tabular}

Table 2: Design variables used to parametrize the dynamic model of the organic Rankine cycle system, obtained as described in [12].

\begin{tabular}{ll}
\hline Component & Parameters \\
\hline Once-through boiler & \\
Volume (cold side) & $10.3 \mathrm{~m}^{-3}$ \\
Volume (hot side) & $51.5 \mathrm{~m}^{-3}$ \\
Weight (metal walls) & $45.4 \mathrm{t}$ \\
UA-value & $420.7 \mathrm{~kW} \cdot \mathrm{K}^{-1}$ \\
Recuperator & \\
Volume (cold side) & $1.18 \mathrm{~m}^{-3}$ \\
Volume (hot side) & $13.24 \mathrm{~m}^{-3}$ \\
Weight (metal walls) & $10.23 \mathrm{t}$ \\
UA-value & $390 \mathrm{~kW} \cdot \mathrm{K}^{-1}$ \\
Turbine & \\
Throat flow passage area & $0.040 \mathrm{~m}^{-2}$ \\
Isentropic efficiency & $81.6 \%$ \\
Electric generator efficiency & $98 \%$ \\
Pump & \\
Delivery pressure & $2928 \mathrm{kPa}$ \\
Inlet pressure & $36 \mathrm{kPa}$ \\
Isentropic efficiency & $72 \%$ \\
\hline
\end{tabular}

